\title{
KEKONVERGENAN BARISAN PADA RUANG METRIK MODULAR
}

\author{
Desi Indriyani, Mariatul Kiftiah, Helmi
}

\begin{abstract}
INTISARI
Penelitian ini bertujuan untuk mengkaji konsep ruang metrik, ruang modular dan ruang metrik modular. Ruang metrik adalah pasangan $(X, d)$ dengan X merupakan himpunan tak kosong dan d adalah suatu metrik di X. Konsep ruang metrik dikembangkan menjadi ruang metrik yang dibangun oleh modular disebut dengan ruang metrik modular. Modular yang dinotasikan dengan $\rho$ adalah suatu fungsi yang memenuhi aksioma-aksioma tertentu pada ruang linear. Suatu himpunan yang merupakan subruang linear dengan $\rho(\lambda f)<\infty$ untuk $f$ adalah anggota ruang linear dan $\lambda>0$ disebut sebagai ruang modular yang dinotasikan dengan $Y_{\rho}$. Ruang metrik modular adalah pasangan $\left(X_{\omega}, d_{\omega}\right)$ dengan $X_{\omega}$ merupakan himpunan metrik modular $\omega$ dan $d_{\omega}$ adalah metrik di $X_{\omega}$. Selain mengkaji konsep ketiga ruang, penelitian ini juga membahas kekonvergenan barisan pada masing-masing ruang. Pada ruang modular, suatu barisan $\left\{x_{n}\right\}$ dikatakan konvergen ke $x$ jika $\rho\left(x_{n}-x\right)<\varepsilon$. Pada ruang metrik, suatu barisan $\left\{x_{n}\right\}$ dikatakan konvergen ke $x$ jika $d\left(x_{n}, x\right)<\varepsilon$. Sedangkan di ruang metrik modular, barisan $\left\{x_{n}\right\}$ dikatakan konvergen ke $x$ jika $\omega_{\lambda}\left(x_{n}, x\right) \leq \varepsilon$.
\end{abstract}

Kata kunci: metrik, modular, konvergen

\section{PENDAHULUAN}

Konsep ruang metrik pertama kali diperkenalkan oleh Mourice Fréchet pada tahun 1906[1]. Kemudian, konsep ruang metrik mengalami pengembangan dan salah satu pengembangannya yaitu ruang metrik yang dibangun oleh modular. Modular diperkenalkan pertama kali oleh Nakano pada tahun 1950[2] dan digeneralisasikan oleh Musielak dan Orlicz dalam tulisannya tentang suatu fungsional pada ruang vektor real yang disebut dengan modular[3]. Didefinisikan suatu himpunan yang merupakan subruang linear dengan $\rho(\lambda f)<\infty$ untuk $f$ adalah anggota dari ruang linear dan $\lambda>0$. Himpunan yang didefinisikan tersebut adalah ruang modular.

Selanjutnya, ruang metrik yang dibangun oleh modular disebut dengan ruang metrik modular. Konsep ruang metrik modular diperkenalkan oleh Chistyakov pada tahun 2010[4]. Pada ruang metrik dan ruang modular mempunyai kesamaan sifat kekonvergenan barisannya yaitu barisan yang konvergen mempunyai titik limit yang tunggal dan setiap barisan yang konvergen merupakan barisan Cauchy. Ruang metrik modular yang merupakan ruang metrik dibangun oleh modular akan mempunyai kesamaan sifat kekonvergenan barisan dengan ruang metrik dan ruang modular. Oleh karena itu, penelitian ini membahas mengenai kekonvergenan barisan pada ruang metrik modular. Tujuan dari penelitian ini untuk mengetahui konsep ruang metrik, ruang modular, ruang metrik modular dan kekonvergenan barisan pada masing-masing ruang.

\section{RUANG METRIK}

Ruang metrik merupakan pasangan $(X, d)$ dengan $X$ adalah himpunan yang tak kosong dan $d$ adalah suatu metrik di $X$. Berikut akan dijabarkan definisi dari ruang metrik hingga kelengkapan ruang pada ruang metrik. 
Definisi 1. [1] Diberikan $X$ himpunan yang tak kosong dan fungsi $d: X \times X \rightarrow \mathbb{R}$. Fungsi $d$ dikatakan sebuah metrik jika memenuhi sifat-sifat berikut:

M1) $d(x, y) \geq 0$ untuk setiap $x, y \in X$,

M2) $d(x, y)=0$ jika dan hanya jika $x=y$,

M3) $d(x, y)=d(y, x)$ untuk setiap $x, y \in X$,

M4) $d(x, y) \leq d(x, z)+d(z, y)$ untuk setiap $x, y, z \in X$.

Himpunan $X$ yang dilengkapi dengan suatu metrik $d$ yang dituliskan dengan $(X, d)$ disebut sebagai ruang metrik.

Selanjutnya, diberikan contoh untuk metrik dan ruang metrik pada Contoh 2 sebagai berikut:

Contoh 2. Didefinisikan metrik $d$ pada ruang norm $(\mathbb{R},\|\cdot\|)$ dengan $d(x, y)=\|x-y\|$ untuk setiap $x, y \in \mathbb{R}$. Himpunan $\mathbb{R}$ yang dilengkapi metrik $d$ adalah ruang metrik.

Pada ruang metrik, suatu barisan dikatakan konvergen dan tidak konvergen apabila memenuhi syarat yang terdapat pada Definisi 3. Berikut diberikan definisi tentang barisan yang dikatakan konvergen.

Definisi 3. [5] Barisan $\left\{x_{n}\right\}$ di ruang metrik $(X, d)$ dikatakan kovergen jika untuk setiap $\varepsilon>0$ terdapat $x \in X$ dan bilangan asli $n_{0}$ sehingga untuk setiap $n \geq n_{0}$ dengan $n \in \mathbb{N}$ berlaku

$$
d\left(x_{n}, x\right)<\varepsilon
$$

Setelah diberikan definisi tentang barisan yang dikatakan konvergen, akan diberikan contoh tentang barisan yang dikatakan konvergen sebagai berikut:

Contoh 4. Diberikan ruang metrik $(\mathbb{R}, d)$ dengan $d(x, y)=|x-y|$ untuk setiap $x, y \in \mathbb{R}$. Barisan $\left\{x_{n}\right\}$ dengan $x_{n}=1-\frac{1}{n}$ untuk $n=1,2, \ldots$ adalah barisan yang konvergen ke 1 pada ruang metrik $(\mathbb{R}, d)$.

Setiap barisan yang konvergen akan mempunyai titik limit. Berikut, diberikan teorema tentang ketunggalan titik limit dari barisan yang konvergen.

Teorema 5. [5] Barisan $\left\{x_{n}\right\}$ di ruang metrik yang konvergen mempunyai titik limit yang tunggal.

Bukti :

Diambil sebarang barisan $\left\{x_{n}\right\}$ di ruang metrik $(X, d)$ yang konvergen, katakan konvergen ke $a$ dan ke $b$ dengan $a, b \in X$. Berdasarkan Definisi 3, untuk setiap $\varepsilon>0$ terdapat $n_{1}, n_{2} \in \mathbb{N}$ berlaku

(i) $\quad d\left(x_{n}, a\right)<\frac{\varepsilon}{2}$ untuk setiap $n \geq n_{1}$ dan

(ii) $d\left(x_{n}, b\right)<\frac{\varepsilon}{2}$ untuk setiap $n \geq n_{2}$.

Selanjutnya, diambil bilangan asli $n_{0}=\operatorname{maks}\left\{n_{1}, n_{2}\right\}$ sehingga diperoleh untuk setiap $n \geq n_{0}$ berlaku

$$
\begin{aligned}
d(a, b) & \leq d\left(a, x_{n}\right)+d\left(x_{n}, b\right) \\
& =d\left(x_{n}, a\right)+d\left(x_{n}, b\right)<\frac{\varepsilon}{2}+\frac{\varepsilon}{2}=\varepsilon .
\end{aligned}
$$

Karena $d(a, b)<\varepsilon$ untuk sebarang $\varepsilon>0$ maka berdasarkan M2 untuk $d(a, b)=0$ diperoleh $a=b$.

Selain barisan yang konvergen pada ruang metrik juga terdapat barisan Cauchy. Berikut, diberikan definisi dari barisan Cauchy.

Definisi 6. [5] Barisan $\left\{x_{n}\right\}$ di ruang metrik $(X, d)$ dikatakan barisan Cauchy jika untuk setiap $\varepsilon>0$ terdapat bilangan asli $n_{0}$ sehingga untuk setiap $m, n \geq n_{0}$ dengan $m, n \in \mathbb{N}$ berlaku

$$
d\left(x_{m}, x_{n}\right)<\varepsilon .
$$

Pada barisan Cauchy, ada yang konvergen dan tidak konvergen. Dari konvergen dan tidak konvergennya suatu barisan Cauchy dapat menentukan kelengkapan dari ruang metrik seperti pada definisi berikut:

Definisi 7. [5] Ruang metrik dikatakan lengkap jika setiap barisan Cauchy di dalamnya dikatakan konvergen. 
Selanjutnya, diberikan contoh untuk ruang metrik lengkap dengan barisan Cauchy yang konvergen sebagai berikut:

Contoh 8. Diberikan ruang metrik $(\mathbb{R}, d)$ dengan metrik $d(x, y)=|x-y|$ untuk setiap $x, y \in \mathbb{R}$. Barisan $\left\{x_{n}\right\}$ dengan $x_{n}=\frac{n+1}{n}$ untuk $n=1,2, \ldots$ adalah barisan Cauchy pada ruang metrik $(\mathbb{R}, d)$ dan konvergen ke 1 sehingga ruang metrik $(\mathbb{R}, d)$ adalah ruang metrik lengkap.

\section{RUANG MODULAR}

Modular adalah suatu fungsi yang memenuhi sifat-sifat tertentu pada ruang linear. Sedangkan, ruang modular adalah suatu himpunan yang didefinisikan dengan modular. Berikut diberikan definisi dari modular.

Definisi 9. [2] Diberikan ruang linear $Y$ pada $K(K=\mathbb{C}$ atau $\mathbb{R})$. Sebuah fungsi $\rho: Y \rightarrow[0, \infty]$ disebut modular, jika untuk setiap $f, g \in Y$ memenuhi sifat-sifat sebagai berikut :

(N1) $\rho(f)=0$ jika dan hanya jika $f=0$,

(N2) $\rho(-f)=\rho(f)$,

(N3) $\rho(\alpha f+\beta g) \leq \rho(f)+\rho(g)$ untuk setiap $\alpha, \beta \geq 0$ dengan $\alpha+\beta=1$.

Jika pada (N3) hanya memenuhi sifat berikut :

(N3') $\rho(\alpha f+\beta g) \leq \alpha \rho(f)+\beta \rho(g)$ untuk setiap $\alpha, \beta \geq 0$ dengan $\alpha+\beta=1$,

maka fungsi $\rho$ disebut modular konvex.

Didefinisikan suatu himpunan yang disebut ruang modular sebagai berikut:

Definisi 10. [7] Jika $\rho$ adalah modular di ruang linear $Y$ maka

$$
Y_{\rho}=\{f \in Y ; \rho(\lambda f)<\infty \text { untuk suatu } \lambda>0\}
$$

adalah ruang modular.

Selanjutnya, diberikan contoh modular dan ruang modular sebagai berikut:

Contoh 11. Diberikan ruang norm $(\mathbb{R},\|\cdot\|)$ dengan $\rho(f)=\|f\|$ untuk setiap $f \in \mathbb{R}$. Fungsi $\rho$ adalah modular dan $\mathbb{R}_{\|\cdot\|}$ adalah ruang modular.

Pada ruang modular, terdapat barisan yang dikatakan konvergen jika memenuhi definisi berikut ini :

Definisi 12. [7] Diberikan barisan $\left\{y_{n}\right\}$ dan $y$ pada ruang modular $Y_{\rho}$. Barisan $\left\{y_{n}\right\}$ dikatakan konvergen $-\rho$ jika untuk setiap $\varepsilon>0$ terdapat $n_{0} \in \mathbb{N}$ sedemikian sehingga untuk setiap $n \geq n_{0}$ dengan $n \in \mathbb{N}$ berlaku $\rho\left(y_{n}-y\right)<\varepsilon$.

Selanjutnya, diberikan contoh dari barisan yang konvergen sebagai berikut:

Contoh 13. Diberikan ruang modular $\mathbb{R}_{\|\cdot\|}$ dengan $\rho(f)=\|f\|$ untuk setiap $f \in \mathbb{R}$. Barisan $\left\{y_{n}\right\}$ dengan $y_{n}=\frac{n}{n+2}$ untuk $n=1,2, \ldots$ adalah barisan yang konvergen ke 1 pada $\mathbb{R}_{\|\cdot\|}$

Pada ruang modular, barisan yang dikatakan konvergen mempunyai titik limit. Berikut, diberikan teorema yang membahas ketunggalan titik limit barisan konvergen pada ruang modular.

Teorema 14. [6] Setiap barisan $\left\{y_{n}\right\}$ yang konvergen pada ruang modular $Y_{\rho}$ mempunyai titik limit yang tunggal.

Bukti :

Diambil sebarang barisan $\left\{y_{n}\right\}$ yang konvergen pada ruang modular $Y_{\rho}$, katakan konvergen ke $y_{1}$ dan ke $y_{2}$ dengan $y_{1}, y_{2} \in Y$. Berdasarkan Definisi 12, untuk setiap $\varepsilon>0$ terdapat $n_{1}, n_{2} \in \mathbb{N}$ berlaku

(i) $\quad \rho\left(y_{n}-y_{1}\right)<\frac{\varepsilon}{2}$ untuk setiap $n \geq n_{1}$ dan

(ii) $\quad \rho\left(y_{n}-y_{2}\right)<\frac{\varepsilon}{2}$ untuk setiap $n \geq n_{2}$.

Selanjutnya, diambil bilangan asli $n_{0}=\operatorname{maks}\left\{n_{1}, n_{2}\right\}$ sehingga diperoleh untuk setiap $n \geq n_{0}$ berlaku 


$$
\rho\left(\frac{1}{2} y_{1}-\frac{1}{2} y_{2}\right)=\rho\left(\frac{1}{2} y_{1}-\frac{1}{2} y_{2}+\frac{1}{2} y_{n}-\frac{1}{2} y_{n}\right)=\rho\left(\frac{1}{2}\left(y_{1}-y_{n}\right)+\frac{1}{2}\left(y_{n}-y_{2}\right)\right)
$$

Berdasarkan N3 diperoleh

$$
\rho\left(\frac{1}{2} y_{1}-\frac{1}{2} y_{2}\right)=\rho\left(\frac{1}{2}\left(y_{1}-y_{n}\right)+\frac{1}{2}\left(y_{n}-y_{2}\right)\right) \leq \rho\left(y_{1}-y_{n}\right)+\rho\left(y_{n}-y_{2}\right)<\frac{\varepsilon}{2}+\frac{\varepsilon}{2}=\varepsilon
$$

Karena $\rho\left(\frac{1}{2} y_{1}-\frac{1}{2} y_{2}\right)<\varepsilon$ untuk sebarang $\varepsilon>0$ maka $\rho\left(\frac{1}{2} y_{1}-\frac{1}{2} y_{2}\right)=0$ sehingga berdasarkan (N1) diperoleh $\frac{1}{2} y_{1}-\frac{1}{2} y_{2}=0$ yang berarti $y_{1}=y_{2}$.

Pada ruang modular, barisan dikatakan barisan Cauchy jika memenuhi definisi sebagai berikut:

Definisi 15. [7] Diberikan barisan $\left\{y_{n}\right\}$ dan $y$ pada ruang modular $Y_{\rho}$. Barisan $\left\{y_{n}\right\}$ dikatakan Cauchy$\rho$ jika untuk setiap $\varepsilon>0$ terdapat $n_{0} \in \mathbb{N}$ sedemikian sehingga untuk setiap $n, m \geq n_{0}$ dengan $n, m \in \mathbb{N}$ berlaku $\rho\left(y_{n}-y_{m}\right)<\varepsilon$.

Pada ruang modular, barisan Cauchy mempengaruhi kelengkapan ruang modular apabila barisan Cauchy konvergen dan tidak konvergen seperti pada definisi berikut:

Definisi 16. [3] Ruang modular $Y_{\rho}$ dikatakan ruang modular lengkap jika untuk setiap barisan Cauchy pada modular adalah barisan konvergen.

Selanjutnya, diberikan contoh ruang modular lengkap dengan barisan Cauchy yang konvergen.

Contoh 17. Diberikan ruang modular $\mathbb{R}_{\|\cdot\|}$ dengan $\rho(f)=\|f\|$ untuk setiap $f \in \mathbb{R}$. Barisan $\left\{y_{n}\right\}$ dengan $y_{n}=\frac{n+2}{2 n}$ untuk $n=1,2, \ldots$ adalah barisan Cauchy dan konvergen ke $\frac{1}{2}$ pada $\mathbb{R}_{\|\cdot\| \|}$ sehingga $\mathbb{R}_{\|\cdot\|}$ adalah ruang modular lengkap.

\section{RUANG METRIK MODULAR}

Ruang metrik modular merupakan ruang metrik yang dibangun oleh modular. Pada ruang metrik modular, terdapat suatu fungsi yang disebut dengan metrik modular jika memenuhi aksioma pada definisi berikut:

Definisi 18. [4] Diberikan himpunan tak kosong $X$. Sebuah fungsi $\omega:(0, \infty) \times X \times X \rightarrow[0, \infty]$ (ditulis dengan $\left.(\lambda, x, y) \mapsto \omega_{\lambda}(x, y)\right)$ dikatakan metrik modular di $X$ jika untuk setiap $x, y, z \in X$ dan $\lambda, \mu \in$ $(0, \infty)$ memenuhi aksioma berikut:

O1) $\omega_{\lambda}(x, y)=0$ jika dan hanya jika $x=y$,

O2) $\omega_{\lambda}(x, y)=\omega_{\lambda}(y, x)$,

O3) $\omega_{\lambda+\mu}(x, y) \leq \omega_{\lambda}(x, z)+\omega_{\mu}(z, y)$.

Dari metrik modular, didefinisikan himpunan metrik modular sebagai berikut:

Definisi 19. [4] Diberikan metrik modular $\omega$ di $X$ dan $x_{0} \in X$, didefinisikan himpunan sebagai berikut:

$$
X_{\omega}=X_{\omega}\left(x_{0}\right)=\left\{x \in X: \omega_{\lambda}\left(x, x_{0}\right) \rightarrow 0 \text { untuk } \lambda \rightarrow \infty\right\}
$$

dikatakan sebagai himpunan metrik modular (sekitar $x_{0}$ ).

Pada himpunan metrik modular, terdapat suatu metrik yang didefinisikan sebagai berikut:

Definisi 20. [10] Diberikan metrik modular $\omega$ dan himpunan metrik modular $X_{\omega}$. Didefinisikan

$$
d_{\omega}(x, y)=\inf \left\{\lambda>0: \omega_{\lambda}(x, y) \leq \lambda\right\},
$$

untuk setiap $x, y \in X_{\omega}$. Fungsi $d_{\omega}$ disebut sebagai suatu metrik pada $X_{\omega}$.

Himpunan metrik modular $X_{\omega}$ yang dilengkapi dengan suatu metrik $d_{\omega}$ yang dituliskan dengan $\left(X_{\omega}, d_{\omega}\right)$ disebut sebagai ruang metrik modular.

Selanjutnya, diberikan contoh untuk metrik modular, himpunan metrik modular dan metrik pada himpunan metrik modular sebagai berikut: 
Contoh 21. Didefinisikan $\omega:(0, \infty) \times \mathbb{R} \times \mathbb{R} \rightarrow[0, \infty]$ dengan $\omega_{\lambda}(x, y)=\frac{\|x-y\|}{\lambda}$ untuk setiap $x, y \in \mathbb{R}$ dan $\lambda \in(0, \infty)$. Selanjutnya, dapat ditunjukkan $\omega$ adalah metrik modular dan diambil sebarang $x, x_{0} \in \mathbb{R}$ maka

$$
\lim _{\lambda \rightarrow \infty} \omega_{\lambda}\left(x, x_{0}\right)=\lim _{\lambda \rightarrow \infty} \frac{d\left(x, x_{0}\right)}{\lambda}=\lim _{\lambda \rightarrow \infty} \frac{\left\|x-x_{0}\right\|}{\lambda}=0
$$

Sehingga $X_{\omega}=\mathbb{R}$ dan diperoleh $d_{\omega}$ sebagai berikut

$$
\begin{aligned}
d_{\omega}(x, y) & =\inf \left\{\lambda>0: \omega_{\lambda}(x, y) \leq \lambda\right\} \\
& =\inf \left\{\lambda>0: \frac{\|x-y\|}{\lambda} \leq \lambda\right\} \\
& =\inf \left\{\lambda>0:\|x-y\| \leq \lambda^{2}\right\} \\
& =\inf \{\lambda>0: \sqrt{\|x-y\|} \leq \lambda\} \\
d_{\omega}(x, y) & =\sqrt{\|x-y\|},
\end{aligned}
$$

maka $X_{\omega}=\mathbb{R}$ yang dilengkapi $d_{\omega}$ adalah ruang metrik modular.

Pada ruang metrik modular, didefinisikan suatu barisan yang dikatakan konvergen seperti pada definisi berikut ini:

Definisi 22. [8] Diberikan ruang metrik modular $\left(X_{\omega}, d_{\omega}\right)$ dan barisan $\left\{x_{n}\right\}$ di $\left(X_{\omega}, d_{\omega}\right)$. Barisan $\left\{x_{n}\right\}$ dikatakan konvergen metrik modular atau konvergen- $\omega$ ke $x \in X_{\omega}$ jika untuk setiap $\varepsilon>0$ terdapat $n_{0} \in \mathbb{N}$ sedemikian sehingga untuk setiap $n \geq n_{0}$ dengan $n \in \mathbb{N}$ berlaku

$$
\omega_{\lambda}\left(x_{n}, x\right) \leq \varepsilon
$$

Selanjutnya, diberikan contoh barisan yang dikatakan konvergen pada ruang metrik modular sebagai berikut:

Contoh 23. Diberikan ruang metrik modular $\left(\mathbb{R}, d_{\omega}\right)$ dengan $d_{\omega}=\sqrt{\|x-y\|}$ dan $\omega_{\lambda}(x, y)=\frac{\|x-y\|}{\lambda}$ untuk setiap $x, y \in \mathbb{R}$ dan $\lambda \in(0, \infty)$. Barisan $\left\{x_{n}\right\}$ dengan $x_{n}=\frac{n+1}{n}$ untuk $n=1,2, .$. adalah barisan yang konvergen ke 1 pada ruang metrik modular $\left(\mathbb{R}, d_{\omega}\right)$.

Pada ruang metrik modular, setiap barisan yang konvergen mempunyai titik limit. Berikut, diberikan teorema tentang ketunggalan titik limit barisan yang konvergen pada ruang metrik modular.

Teorema 24. [9] Setiap barisan $\left\{x_{n}\right\}$ yang konvergen di ruang metrik modular $\left(X_{\omega}, d_{\omega}\right)$ mempunyai titik limit yang tunggal.

Bukti :

Diambil sebarang barisan $\left\{x_{n}\right\}$ yang konvergen di ruang metrik modular $\left(X_{\omega}, d_{\omega}\right)$, katakan konvergen ke $x_{1}$ dan ke $x_{2}$ dengan $x_{1}, x_{2} \in X_{\omega}$. Berdasarkan Definisi 22, untuk setiap $\varepsilon>0$ terdapat $n_{1}, n_{2} \in \mathbb{N}$ berlaku

(i) $\omega_{\lambda}\left(x_{n}, x_{1}\right) \leq \frac{\varepsilon}{2}$ untuk setiap $n \geq n_{1}$, dan

(ii) $\omega_{\mu}\left(x_{n}, x_{2}\right) \leq \frac{\varepsilon}{2}$ untuk setiap $n \geq n_{2}$.

Selanjutnya, diambil bilangan asli $n_{0}=\operatorname{maks}\left\{n_{1}, n_{2}\right\}$ sehingga diperoleh untuk setiap $n \geq n_{0}$ berlaku

$$
\begin{aligned}
\omega_{\lambda+\mu}\left(x_{1}, x_{2}\right) & \leq \omega_{\lambda}\left(x_{1}, x_{n}\right)+\omega_{\mu}\left(x_{n}, x_{2}\right) \\
& =\omega_{\lambda}\left(x_{n}, x_{1}\right)+\omega_{\mu}\left(x_{n}, x_{2}\right) \leq \frac{\varepsilon}{2}+\frac{\varepsilon}{2}=\varepsilon .
\end{aligned}
$$

Karena $\omega_{\lambda+\mu}\left(x_{1}, x_{2}\right) \leq \varepsilon$ untuk sebarang $\varepsilon>0$ maka berdasarkan $\mathrm{O} 1, \omega_{\lambda+\mu}\left(x_{1}, x_{2}\right)=0$ sehingga diperoleh $x_{1}=x_{2}$. 
Pada ruang metrik modular, barisan dikatakan barisan Cauchy bila memenuhi definisi sebagai berikut: Definisi 25. [8] Diberikan ruang metrik modular $\left(X_{\omega}, d_{\omega}\right)$ dan barisan $\left\{x_{n}\right\}$ di $\left(X_{\omega}, d_{\omega}\right)$. Barisan $\left\{x_{n}\right\}$ dikatakan barisan Cauchy metrik modular atau Cauchy- $\omega$ ke $x \in X_{\omega}$ jika untuk setiap $\varepsilon>0$ terdapat $n_{0} \in \mathbb{N}$ sedemikian sehingga untuk setiap $m, n \geq n_{0}$ dengan $m, n \in \mathbb{N}$ berlaku

$$
\omega_{\lambda}\left(x_{m}, x_{n}\right) \leq \varepsilon
$$

Barisan Cauchy yang konvergen dan tidak konvergen mempengaruhi kelengkapan ruang pada ruang metrik modular seperti yang terdapat pada definisi berikut :

Definisi 26. [8] Ruang metrik modular dikatakan lengkap jika setiap barisan Cauchy pada metrik modular adalah barisan konvergen.

Berikut, diberikan contoh ruang metrik modular lengkap dengan barisan Cauchy yang konvergen.

Contoh 27. Diberikan ruang metrik modular $\left(\mathbb{R}, d_{\omega}\right)$ dengan $d_{\omega}=\sqrt{\|x-y\|}$ dan $\omega_{\lambda}(x, y)=\frac{\|x-y\|}{\lambda}$ untuk setiap $x, y \in \mathbb{R}$ dan $\lambda \in(0, \infty)$. Barisan $\left\{x_{n}\right\}$ dengan $x_{n}=\frac{n+2}{n^{2}}$ untuk $n=1,2, .$. adalah barisan Cauchy dan konvergen ke 0 pada ruang metrik modular $\left(\mathbb{R}, d_{\omega}\right)$ sehingga ruang metrik modular $\left(\mathbb{R}, d_{\omega}\right)$ adalah ruang metrik modular yang lengkap.

\section{PENUTUP}

Berdasarkan analisis dan pembahasan yang telah dijabarkan, dapat disimpulkan bahwa ruang metrik modular adalah himpunan metrik modular $X_{\omega}$ yang dilengkapi dengan suatu metrik $d_{\omega}$ yang dituliskan dengan $\left(X_{\omega}, d_{\omega}\right)$. Pada ruang metrik modular, jika barisan $\left\{x_{n}\right\}$ konvergen ke $x$ maka berlaku $\omega_{\lambda}\left(x_{n}, x\right) \leq \varepsilon$. Ruang metrik modular mempunyai kesamaan sifat kekonvergenan barisan dengan ruang metrik dan ruang modular

\section{DAFTAR PUSTAKA}

[1] Bartle RG, Sherbert DR. Introduction to Real Analysis. United States of America: John Wiley \& Sons; 2000.

[2] Sadeghi G. On The Orthogonal Stability of The Pexiderized Quadratic Equations in Modular Spaces. Tamsui Oxford Journal of Information an Mathematical Sciences. 2013; 29(3): 295307.

[3] Musielak J, Orlicz W. On Modular Space. Studi Matematika. 1959; 18:49-65.

[4] Chistyakov VV. Modular Metric Spaces I: Basic Concepts. Nonlinear Analysis. 2010; 72:1-14.

[5] Darmawijaya S. Pengantar Analisis Abstrak. Yogyakarta: UGM; 2007.

[6] Musielak J. Orlicz Space and Modular Space. Germany: Springer-Verlag Berlin Heidelberg; 1983.

[7] Supama. On Some Common Fixed Point Theorem in Modulared Spaces. International Mathematical Forum. 2012; 7(52):2571-2579.

[8] Chistyakov VV. A Fixed Point Theorem for Contractions in Modular Metric Spaces. ArXiv eprint. 2018.

[9] Chistyakov VV. Modular Metric Spaces Theory and Applications. Rusia: Springer; 2015.

[10] Abobaker H, Ryan RA. Modular Metric Spaces. Irish Mathematical Society Bulletin. 2010; 110.

DESI INDRIYANI : Jurusan Matematika FMIPA UNTAN, Pontianak desi271296@student.untan.ac.id

MARIATUL KIFTIAH : Jurusan Matematika FMIPA UNTAN, Pontianak kiftiahmariatul@math.untan.ac.id

HELMI : Jurusan Matematika FMIPA UNTAN, Pontianak helmi132205@yahoo.co.id 